\section{Adminitrasi Sarana Dan Prasarana}

\author{
Nola nopita \\ Universitas Negeri Padang \\ Indonesia \\ E-mail : \\ nollanopita@gmail.com
}

\begin{abstract}
In the world of education, there are several components of education that are very instrumental in supporting learning activities both directly and indirectly. One of the most important components is educational facilities and infrastruncture.

Administration of educational facilities and infrastructure is a very supportive thing for achieving the goals of education. The teaching and learning process will be more succesful if educational facilities and infrastucture are adequate. Education infrastructure and facilities must always be complete. The government must always strive to continuously aquip aducational facilities and infrastructure for all levels and levels of education. this article aims to determine the administration of educational facilities and infrastructure in Indonesia along with the obstacles faced and the efforts taken to overcome these obstacles. This research is a descriptive study with a qualitative approach. Data collection is done by the method of observation, interviews and documentation. The data analysis technique in this study is an interactive analysis consisting of data reduction, data presentation and conclusion drawing. Check the validity of the data using source triangulation and method triangulation.
\end{abstract}

Metode penelitian ini berisi tentang bagaimana metode penelitian ini dilakukan. Artikel ilmiah hendaknya disusun dengan metode dan langkah-langkah yang sistematis untuk memudahkan melakukan penelitian. Pada artikel ini, peneliti menggukan metode studi literatur dengan cara mengumpulkan literatur (bahan-bahan materi) yang bersumber dari buku, jurnal, dan sumber lainnya terkait tentang Administrasi Sarana dan Prasarana. Sumber sumber yang terkait adalah mengenai pengertian administrasi pendidikan, proses administrasi pendidikan dan juga peranan guru dalam administrasi pendidikan. Dalam kesempatan kali ini peneliti menggunakan metode kualitatif deskriptif, yaitu metode yang digunakan untuk mencari unsur unsur, ciri ciri, dan sifat sifat suatu fenomena. Metode ini dimulai dengan mengumpulkan data, menganalisis data, dan menginterpretasikannya.

III. KAJIAN TEORI DAN PEMBAHASAN A. Pengertian Administrasi Sarana dan Prasarana Kata administrasi berasal dari bahasa latin "ad" dan "ministro", yang mempunyai arti "kepada" dan "melayani". Administrasi dapat diartikan pelayanan atau pengabdian kepada subyek tertentu. Secara istilah administrasi yaitu upaya mencapai tujuan sacara efektif dan efisien dengan memanfaatkan orang-orang dalam suatu pola kerjasama. Menurut kamus besar Bahasa Indonesia sarana adalah segala sesuatu yang dapat dipakai sebagai alat dalam mencapai maksud atau tujuan. Sedangkan prasarana adalah segala sesuatu yang merupakan penunjang utama terselenggaranya suatu proses( usaha, pembangunan, proyek).

1

Judul Artikel, Padang 2019

Sedangkan secara etimologis (bahasa) prasarana berarti alat tidak langsung untuk mencapai tujuan dalam pendidikan. misalnya: lokasi/tempat, bangunan sekolah,lapangan olahraga, uang,dsb. Sedangkan sarana berarti alat langsung untuk mencapai tujuan pendidikan. misalnya; ruang, buku, perpustakaan, laboratorium dan sebagainya. Dapat disimpulkan bahwa administrasi sarana dan prasarana adalah sesuatu hal yang dirangcang dan diatur dengan sebaikbaiknnya yang berupa barang atau gedunng dengan memiliki tujuan tertentu dalam mewujud pendidikan yang baik. 
B. Proses Administrasi Sarana dan Prasarana 1) Perencanaan

Merupakan penyusunan rangkaian keputusan secara sistematis dan rasional tentang sarana dan prasarana yang dibutuhkan, bagaimana spesifikasinya, keurgensinya, cara pengadaannya, waktu pengadaan, dan biaya pengadaan Perencanaan kebutuhan sarana dan prasarana pendidikan merupakan pekerjaan yang kompleks, karena harus terintegrasi dengan rencana pembangunan baik nasional, regional maupun local. Perencanaan ini merupakan system perencanaan terpadu dengan perencanaan pembangunan tersebut.

Kebutuhan sarana dan prasarana pendidikan tergantung pada jenis program pendidikan dan tujuan yang di tetapkan. a.Perencanaan pengadaan tanah untuk gedung atau bangunan $s$ ekolah $b$. Perencanaan pengadaan bangunan gedung sekolah $\mathrm{c}$. Perencanaan pembangunan bangunan gedung sekolah d.Perencanaan pengadaan perabot dan pelengkapan pendidika $\mathrm{n}$ e. Pengadaan sarana dan prasarana pendidikan f. Inventasi sarana dan prasarana pendidikan g.Pemeliharaan sarana dan prasarana pendidikan h.Penggunaan sarana dan prasarana pendidikan i. Penghapusan sarana dan prasarana pendidikan

Dalam penyusunan perencanaan dapat ditempuh beberapa cara, diantaranya: a. Analisis kebutuhan. Kegiatan untuk mendapatkan informasi mengenai jenis, jumlah, kualitas, saran dan prasarana pendidikan yang dibutuhkan oleh sekolah, dengan mempertimbangkan: perkembangan kebutuhan sekolah, penggantian barangbarang yang rusak, hilang, atau dihapuskan serta keperluan persediaan barang (Sutjipto 1993) b. Mengumpulkan data dan informasi mengenai sarana dan prasarana yang ada c. Penyusunan rencana kebutuhan sarana dan prasarana pendidikan

\section{2) Pengadaan Sarana dan Prasarana Pendidikan}

Pengadaan merupakan segala kegiatan untuk menyediakan semua keperluan barang, benda dan jasa bagi keperluan pelaksanaan tugas. Dengan kata lain merupakan upaya merealisasikan rencana kebutuhan pengadaan perlengkapan yang telah disusun sebelumnya, antara lain: Pengadaan tanah dapat dilakukan dengan cara membeli, menerima hibah, menerima hak pakai, dan menukar.

Pengadaan bangunan bisa dilakukan dengan membangun bangunan baru, membeli bangunan, menyewa bangunan ataupun menerima hibah bangunan. Pengadaan perabot, Pengadaan sarana pendidikan, alatalat kantor dan Alat Tulis Kantor (ATK) bisa dilakukan dengan cara membeli, menerbitkan sendiri, dan menerima bantuan/ hadiah/ hibah.

Pengadaan kendaraan atau alat transportasi bisa dilakukan dengan membeli, menerima bantuan dan lain-lain. Pengadaan peralatan harus memperhatikan aspek kualitas, kuantitas, hukum, dan prosedur yang berlaku dalam pengadaan sarana dan prasarana tersebut. Pengadaan sarana dan prasarana pendidikan dapat dilakukan dengan:

a.tanah, dapat dilakukan dengan membeli, hibah, hak pakai, sewa, dan tukar guling. b.Gedung, dapat diakukan dengan membei, membangun baru, hibah, hak pakai, sewa dan tukar pakai. c.Peralatan dan perlengkapan, dapat dilakukan dengan membeli, membuat sendiri, sewa, hibah, hak 
pakai. d. Pengadaan kendaraan atau alat transportasi bisa dilakukan dengan membeli, menerima bantuan dan lain lain.

\section{3) Inventaris Sarana dan Prasarana Pendidikan}

Merupakan kegiatan mancatat dan menyusun daftar sarana dan prasarana yang ada secara teratur menurut ketentuan yang berlaku kedalam suatu daftar inventaris barang yang berfungsi sebagai data yang diperlukan dalam perencanaan, pengadaan, penyaluran, pemeliharaan, penghapusan, pengendalian serta pengawasan sarana dan prasarana.

Salah satu aktivitas dalam pengelolaan perlengkapan pendidikan di sekolah adalah mencatat semua perlengapan yang dimiliki oleh sekolah. Lazimnya, kegiatan pencatatan semua perlengkapan itu disebut dengan istilah inventarisasi perlengkapan pendidikan. Kegiatan tersebut merupakan suatu proses yang berkelanjutan.

Tujuan Inventarisasi - Tercipta ketertiban administrasi barang - Penghematan keuangan - Mempermudah pemeliharaan dan pengawasan barang - Menyediakan data informasi untuk perencanaan Manfaat inventarisasi

\section{2}

Judul Artikel, Padang 2019

- mencatat dan menghimpun data aset yang dikuasahi unit organisasi/ departemen. Menyiapkan dan menyediakan bahan laporan pertanggung jawaban atas penguasaan dan pengelolaan aset organisasi/negara. - Menyiapkan dan menyediakan bahan acuan untuk pengawasan aset organisasi atau negara. Menyediakan informasi mengenai aset organisasi /negara yang dikuasai departemen sebagai bahan untuk perencanaan kebutuhan, pengadaan dan pengelolaan perlengkapan departemen. -Menyediakan informasi tentang aset yang dikuasai departemen untuk menunjang perencanaan dan pelaksanaan tugas departemen.

4) Pengelolaan/Perawatan Sarana dan Prasarana Pendidikan

Pemeliharaan atau perawatan adalah kegiatan rutin untuk mengusahakan agar barang tetap dalam kegiatan baik dan berfungsi dengan baik juga. Kegiatan pemeliharaan dapat dilakukan menurut ukuran waktu dan ukuran keadaan barang (setiap hari, secara berkala atau jangka waktu tertentu sesuai dengan petunjuk penggunaan). Pemeliharaan dapat dilakan oleh pemegangnya / penanggungjawabnya. Pemeliharaan bisa juga dengan memanggil tukang / ahli servis,setiap habis dipakai sarana dan prasarana kembali di bersihkan dan disimpan di tempat semula. Pada prinsipnya kegiatan pemeliharaan dilakukan agar setiap sarana dan prasarana itu senantiasa siap pakai dalam prosem belajar mengajar. Aktivitas, kreativitas dan rasa tanggung jawab adalah kunci dari keberhasilan kegiatan pemeliharaan . 5) Penghapusan Sarana dan Prasarana Pendidikan

Merupakan kegiatan mengeluarkan barangbarang meilik negara/ daerah atau sekolah dari daftar inventaris berdasarkan peraturan perundang-undangan yang berlaku. Syaratsyarat pertimbangan penghapusan inventaris barang antara laian:

a. Dalam keadaan rusak berat, tidak dapat digunakan atau diperbaiki lagi b. Perbaikan memerlukan biaya yang besar c. Penyusutan diluar kemampuan pengurus 
barang d. Sudah kadarluarsa e. Merupakan barang kelebihan yang jika disimpan lebih lama akan rusak f. Musnah angkibat bencana alam, hilang/ dicuri atau diselewengkan

Langkah-langkah penghapusan barang inventaris:

a. Penilaian barang yang akan dihapus dilakukan setiap tahun, bersama dengan waktu memperkirakan kebutuhan b.Memperhitungkan tahun-tahun penyingkiran dan penghapusan ditinjau dari segi nilai uang c. Membuat surat pembertahuan kepada atasan bahwa akan diadakan penghapusan barang dengan menyebutkan barangbarang yang akan dihapuskan d. Melaksanakan penghapusan bila telah mendapat persetujuan atau memenuhi syarat-syarat yang telah ditentukan. e. Membuat berita acara penghapusan

Penghapusan sebagai salah satu fungsi administrasi sarana pendidikan mempunyai arti :

a. Mencegah kerugian atau pemborosan dari biaya perbaikan $b$. Meringankan beban kerja dan tanggung jawab pelaksanaan inventaris c. Membebaskan satuan organisasi dalam pengurusan barang yang tidak produktif lagi. d.Membebaskan ruangan atau perkarangan kantor dari penumpukan barang yang tidak di pergunakan.

C. Peranan Guru dalam Administrasi sarana dan prasarana dan pengelolanya Peranan Guru dalam Administrasi sarana dan Prasarana antaara lain dengan cara : 1) Sebagai seorang personal administrasi pendidikan berusaha untuk menjaga sarana danprasarana dalam proses pembelajaran, dan juga harus menanamkan kepada siswakedisiplinan dalam memakai suatu barang disekolah serta memberikan pengawasan kepada siswayang memakai alat-alat disekolah.

IV. KESIMPULAN Sarana dan prasarana adalah segala sesuatu yang digunakan untuk mencapai pembelajaran yang efektif dan efisien. Dan juga sarana dan prasarana juga harus kita jaga supaya bisa tahan lama dan bisa kita pakai untuk jangka panjang supaya terwujud pendidikan yangbaik dengan adanya sarana dan prasarana yang baik . Dengan memiliki sarana dan prasarana yang baik insya allah pendidikan kita akan lebih baik kedepanya. Daftar Pustaka Arikunto, Suharsimi. 2003.Manajemen Berbasis Sekolah. Jakarta: Raja Grafindo Perkasa Hani, Ami Amalia 2012."Pengelolaan Sarana dan Prasarana Pendidikan". Syahril, dkk. 2009 "Profesi Kependidikan". Padang:UNP 